witnesses are often vague, conflicting, and quite unreliable for the data required to fix the real path above the earth. It seems, however, very probable that the fireball which lit up the countryside from which it was seen (including North Yorkshire, Derbyshire and Westmorland) was associated with the Perseid shower of meteors. This shower, which provides a high maximum frequency of meteors between August 10 and 12, is really operative from about mid-July until after mid-August; during this period the radiant point moves progressively from a position at about R.A. $\mathrm{l}^{\text {h }}:$ Dec. $+50^{\circ}$ to R.A. $4^{\text {h }}$ : Dec. $65^{\circ}$, or from a position in the constellation Andromeda, through Perseus (which gives the shower its name) to Camelopardus.

\section{The Night Sky in September}

THe night sky of September offers a rich variety of objects for observation with slight optical aid. Some of the most attractive of the constellations are visible; there are star fields of the Milky Way, the Andromeda Nebula, the variable star, Algol, the Pleiades, some of the best known double stars and the largest two major planets. Between the first and last days of the month, the days shorten in the latitude of London by nearly two hours. On Sept. $23^{\mathrm{d}} 5^{\mathrm{h}}$ the sun enters, at the autumnal equinox, the sign Libra. Full moon occurs on Sept. $1^{\mathrm{d}} 12 \frac{1 \mathrm{~h}}{2}$ and again, as the Harvest Moon, on Sept. $30^{\mathrm{d}} 21^{\mathrm{h}}$. Of the planets to be observed, Venus still sets in the early twilight, but Jupiter is a bright object low in the south-west during the early evening. There is yet time, though very limited, for observing some interesting phenomena--transits, occultations and eclipses-associated with the four inner satellites. Particulars will be found on p. 615 of the Nautical Almanac for 1936. Saturn is above the horizon all night; on September 12 it is in opposition at a least distance from the earth of about 800 million miles. The rings appear nearly closed, the minor axis subtending an angle of only $1 \frac{1}{2}$ seconds of arc. Mars is a morning star, and will be in conjunction with the bright star Regulus on September 24, when the angular distance between planet and star is less than $1^{\circ}$. Uranus is in Aries, and can be found near the 6th magnitude star $\omega$ Arietis, which the planet resembles when viewed with binoculars; but a 2 - or 3 -inch telescope will show the planet's disk of $3 \frac{1}{2}$ " in diameter. The light variation of Algol ( $\beta$ Persei) may be observed near the following times of minima : Sept. $3^{\mathrm{d}} 3^{\mathrm{h}}, 6^{\mathrm{d}} 0^{\mathrm{h}}, 26^{\mathrm{d}} 2^{\mathrm{h}}, 28^{\mathrm{d}} 23^{\mathrm{h}}$, Oct. $1^{\mathrm{d}} 19^{\mathrm{h}}$ (add $\mathrm{l}^{\mathrm{h}}$ to convert to Summer Time). The following double stars are suitably placed for observation during September : $\alpha$ Herculis (separation of components $\left.41_{2}^{\prime \prime}\right)$, $\varepsilon$ Lyræ $\left(3^{\prime}\right.$ separation for the wide components each of which is a double of $2 \frac{1}{2}$ and $3^{\prime \prime}$ separation respectively), $\beta$ Cygni $\left(34^{\prime \prime}\right)$ and $\gamma$ Delphini $\left(11^{\prime \prime}\right)$. .

\section{Announcements}

Prof. Max Planck, president of the Kaiser Wilhelm Society for the Advancement of Science, has been nominated doctor honoris causa by the Faculty of Philosophy of the University of Graz.
The 1936 American Physical Education honorary award for achievement has been divided between the twin brothers, Dr. Edgar and Dr. Edwin Fauver, directors of physical education at Wesleyan University and Rochester University, respectively.

ON the occasion of the recent celebration of the twenty-fifth anniversary of the German Statistical Society the following were nominated honorary members: Prof. Sigmund Schott, director of the Mannheim Statistical Office; Dr. Friedrich Prinzing, of Ulm; Dr. Kovacs, president of the Hungarian Central Statistical Office, Budapest ; and Dr. Savorgnan, president of the Italian Central Statistical Office, Rome.

Dr. Wullibald Scholz, professor of neurology and psychiatry at Munich, has succeeded the late Prof. Spielmeyer as director of the Department of Cerebral Pathology of the German Research Institute of Psychiatry, Kaiser Wilhelm Institute, Munich.

A NUMBer of public health courses have been instituted in Holland for training civilians in protecting themselves against attacks from enemy aeroplanes.

A six-year study of the role of diet in the last half of adult life will be undertaken at the New York State College of Agriculture at Cornell University. The Rockefeller Foundation has contributed 42,500 dollars to the support of the study.

THE second Italian Congress of Radiology will be held at Modena on September 20-21 under the presidency of Prof. Ruggero Balli, director of the Institute of Radiology. Further information can be obtained from the general secretary, Dr. Marco Lenzi, Istituto di Radiologia, Modena.

Prof. Pavlov's widow has presented the first batch of papers formerly belonging to her husband to the archives of the Academy of Sciences of Soviet Russia. They consist of about 2,500 letters from Russian and foreign men of seience. Most of them relate to the years following the Revolution, while among the earlier ones are several from Metchnikoff and other famous men of science who corresponded regularly with Pavlov.

Applicatrons are invited for the following appointments, on or before the dates mentioned :

An assistant (III) at the Ditton Laboratory, East Malling, Kent (refrigeration)-The Superintendent, Ditton Laboratory, East Malling, Kent (August 31).

Three inspectors (agricultural and live-stock) in the Department of Agriculture for Scotland-The Secretary (Establishment Branch), Department of Agriculture for Scotland, York Buildings, Queen Street, Edinburgh, 2 (September 1).

A civilian education officer in the Royal Air Force Educational Service-The Secretary (A.E.), Air Ministry, Adastral House, Kingsway, London, W.C.2 (September 14).

A visiting tutor for educational psychology in the Catholic Training College for Women, Cavendish Square, London, W.1-The Principal. 